\title{
Nature-based management of urban floods to decline risks with case studies
}

Abdol Aziz Shahraki

\begin{abstract}
This paper discusses devastating urban floods in the year 2019 that caused human and socioeconomic losses in many countries, including Iran. The main question addressed by this paper is the choice between two flood management models, namely, the optimal and naturebased flood management or the existing hazardous situation that damage the ecosystem and natural resources. The analysis of this paper will find the main responsible factors in the mentioned floods in Iran. For this reason, it examines the impacts of the existing flood management that neglects the ecosystems, environmental components, and nature. The method of this research includes theoretical studies, case studies with the help of structured interviews, and observations. A benchmarking technique compares the two alternatives. The comparisons use seven indicators abstracted from successful global experiences and local knowledge. Finally, this research presents a model for optimal flood management that is applicable everywhere in the world.
\end{abstract}

\section{Keywords:}

Flood management; ecosystems; climate change; indicators; benchmarking; nature-based

\section{Introduction}

Middle Eastern countries, including Iran, experienced heavy and persistent rains in late March and April 2019. The rains made widespread floods with significant social and economic impacts (Salimi \& Al-Ghamdi, 2020). The intensity of the rains, coupled with the nature of the terrain, caused deadly flash floods (NASA Earth Observatory). Many parts of the north, west, center, east, southeast, and southwest of Iran experienced mortal and destructive floods. The following map shows the vast scope of the floods in Iran. 


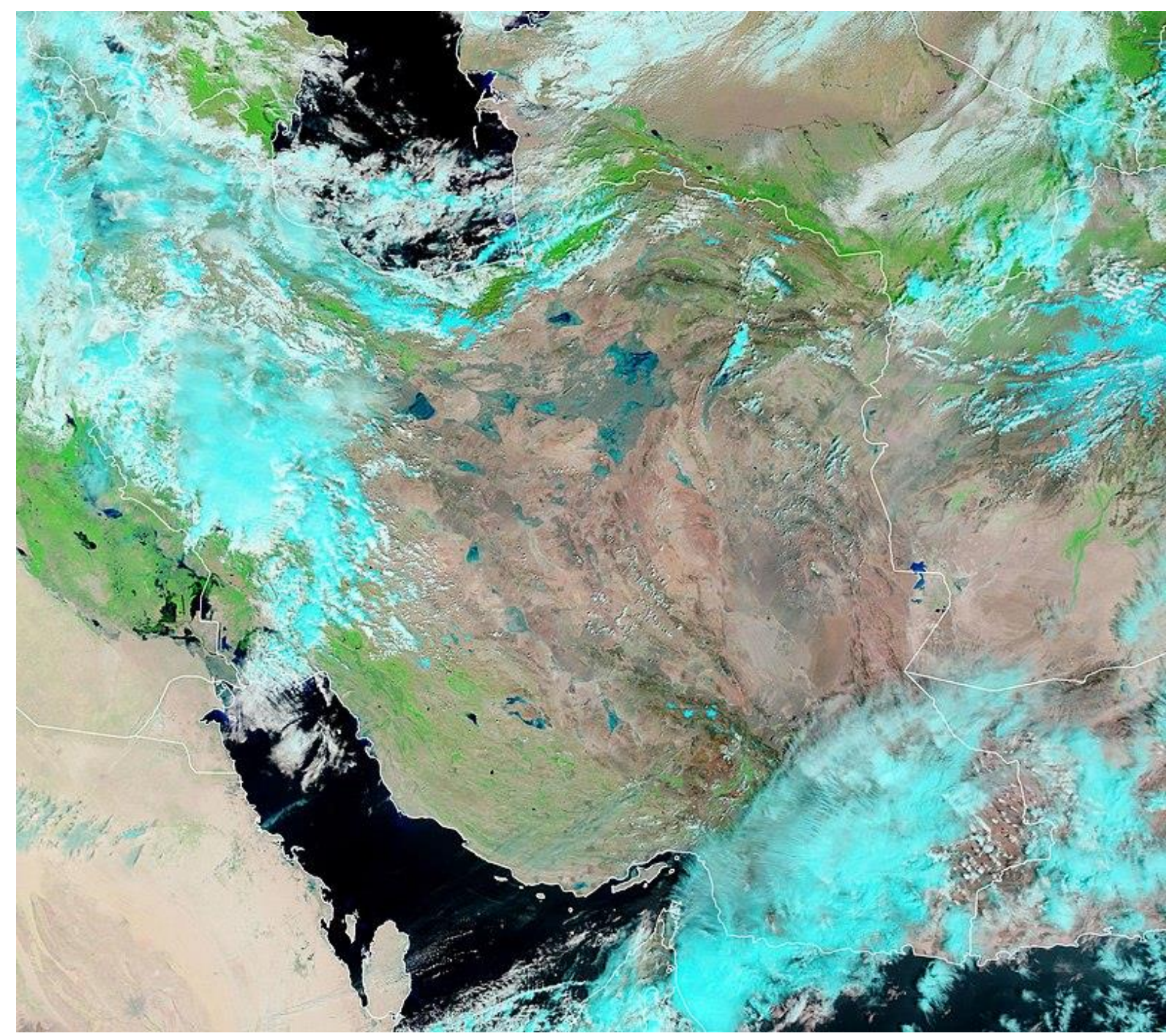

Figure 1. The scope of the 2019's floods in Iran

Source: NASA Earth Observatory images accessible online at https://earthobservatory.nasa.gov/images/144785/floods-ravage-iran-and-iraq

Figure 1 shows the areas affected by the floods. On the map, you can see that cities in the west and south of the Caspian Sea, and the north and northwest of Iran that are flooded. The map exhibits the flooded western regions of Iran from the northern part down to the southwest, above the Persian Gulf in Khuzestan province as well. The map similarly shows the flood-affected areas in central and southern central provinces such as Fars province. In addition, floods originated from Afghanistan attacked the Sistan region in the southeast of Iran. Southern areas of Baluchistan in Iran and northern Oman Sea have been flooded too. Overall, the flood-affected regions experienced catastrophic human, financial, infrastructure, and urban and rural causalities. The quantity of the total damages has not been determined, but there are many reasons to claim that the hazards are widespread and heavy costly. The 
floods affected the political, social, and economic situations of Iran extensively. Of course, these floods could increase the groundwater resources of Iran. Nevertheless, due to the lack of necessary technologies and infrastructure to direct the waters into groundwater, the beneficial side of the floods has been shrunk (Pakmehr et al 2020). Therefore, the extent and severity of the floods highlight the importance of flood control and management. In common with Tockner and Standford, we believe that flood management is a vital task now (Tockner \& Stanford, 2002). From the other side, the effects of ever-expanding urban developments on the hydrological cycle are large. Amid the mentioned massive floods in Iran, debates about the causes of the floods have increased. Some scholars are saying that the neglecting of the environment, lack of knowledge-based urban planning, absence of funding for standard constructions caused the hazardous floods (Pourghasemi et al 2020). They argue that forests are declining and the incompetent authorities do not respect the structural standards, urban building codes, and regulations. Therefore, floods have become so mortal and destructive. On the contrary, others are saying that climate changes and sudden rains are only responsible for the recent fatal floods (Yadollahie, 2019).

The question addressed by this research is which factor is the reason for the hazardous floods? In other words, the question is whether poor control and management of floods lead to devastating floods or climate changes. To answer this question, this paper will look at how the authorities treated the ecosystems and the natural cycle of water flows in Iran. Do they behave abusively with Iran's nature? This paper also investigates whether a significant climate change has happened in Iran.

The purpose of this research is to introduce an optimal model for the control and management of floods to prevent hazards in advance.

The methods of this research are both theoretical studies and field observations to achieve the goal some classic methods and a benchmarking technique have been applied as well.

The outcome of this study is an optimal model for flood control projects to minimize the harms of the floods.

\section{Theoretical studies}

This part studies the causes of floods with mortal hazards in the urban built environments in the views of water and flood engineering and management. The purpose of theoretical studies is to provide a theoretical guide for field observation. It is necessary to understand to what degree human activities cause the floods. Earlier, scholars discussed the concept of optimal 
management of floods (Ghobadi \& Kaboli, 2020; Raso et al 2019 and Shahraki, 2015). In common with the scholars, with optimal flood management we mean using knowledge-based methods thru minimal budget, maximal ecosystem maintenance, and maximum damage prevention. According to a definition of the Webster Dictionary flood is 'a rising and overflowing of a body of water especially onto normally dry land'. Floods occur in rivers, waterways, channels and water storages like lakes, swamps and dams. Thus, the definition means that an overflow of water can take place on usually dry lands. Shortages of natural or artificial drainages lead the excess of surface runoff (Müller et al, 2019; Singh, 2019; Hong et al 2018; Chan et al 2018 and Spaans \& Waterhout, 2017). The shortages of drainage systems cause major human, infrastructure, economic, and socio-psychological hazards. The increase in the population and the simultaneous increase in urbanization has been a fast-paced trend in the developing countries (Zhang, 2016). World Bank studies In Iran show that the percentage of the urbanization trend in recent decades has increased. Please see the fact in Figure 2.

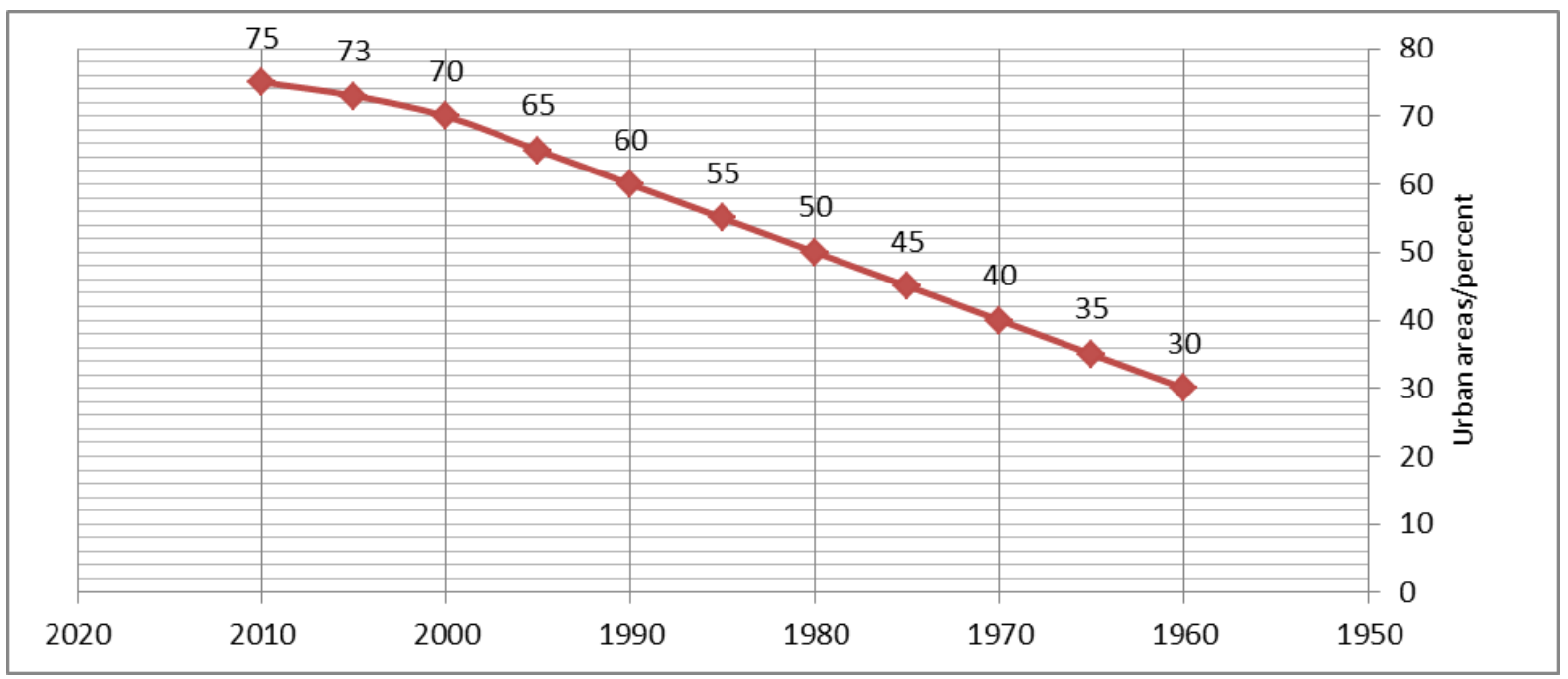

Figure 2. Expansion of urbanization in Iran during recent decades

Source: The World Bank

Figure 2 shows that the urban built environments area has jumped from 30\% in 1960 up to $75 \%$ in 2010 . The development of urban areas has numerous effects on water resources, water circulation in nature, rivers and natural drainage, and flood behavior. In addition, the need for hydraulic structures and artificial drainage for flood engineering and their control should be placed at the center of urban plans and designing. Many scholars verify the multidimensional effects of Urbanism's expansion in the flood (Rogger et al, 2017, Walsh et al, 2016 and Fetter, 2018). 
One major impact of the urbanization is degrading of the ecosystems and natural environments. Scholars examined the effects of population growth and urbanization on the ecosystems. They evaluated ongoing water supply projects. The evaluations have proven that the majority of the current water supply policies are destructive. The results of the studies state that water procurement policies should not include projects that harm natural watercourses nor ecosystems (Peng et al 2017). One explicit result of the expansion of urbanization is the reduction of soil quality. The other is the coverage of the earth's surface with the building materials. The expansion of the urban built environments narrows the watercourses and rivers. It shortens the water shelf life on the lands. Consequently, the rains are moving rapidly towards low-lying urban areas (Corbau et al, 2019 and Fekete \& Bogárdi, 2015). The covering of the land surface by a greater share of impervious building materials means that a plentiful bigger proportion of any rainfall forms directly floods. In addition, the grounds covered by buildings in a city, the paved streets and car parks cover large surfaces. Considering the local topographic characteristic, any slope of the land also enhances the overflow response of a paved area. In every catchment area, the effect on the stream discharge is dependent on the degree of the impervious area. The influence of groundwater is limited to rainfall infiltration into the soil. Thus, after major urban developments in a catchment, the following differences in the river flow will be identified. The emergence of water in the streets and residential areas, a steeper rising curve of the flow, increase in the flood peak magnitude, and decline of water quality by pollutions.

The expansion of urbanization makes essential structural changes to drainage channels and declines their capacity. Flood information can help communities reduce their vulnerability to floods (Han et al 2016 and Metal, 2017). Therefore, by increasing the urban areas, the volume of the water flow in the city increases, while the drainage capacity is reduced. Rapid urbanization is making people vulnerable to the effects of climate variability. The most obvious change in climate caused by urbanization is an increase in the sudden and sharp floods. An increase in the average temperature happens too. Miller and Hutchins studied the impacts of urbanization on climate change and consequently the situations of urban flooding. They concluded that urbanization poses climate change with high spatial-temporal variability and uncertainty in climate (Miller and Hutchins, 2017). The majority of the scholars agree that the increased urbanization made global warming. They believe that global warming is caused by $\mathrm{CO}^{2}$-based greenhouse gases. Human activities affect climate change through greenhouse gas emissions and land-use changes (Wang et al, 2014). 
Urban spatial development affects forests and green lands negatively. Reinmann et al assessed the effects of urban expansion on global warming from 2005 to 2050 . The assessment found that the expansion of human settlements causes land-use and land cover changes. The study used the state of Massachusetts for quantifying the effects. The study assessed the impacts of the projected expansion of human settlements on the biophysical nature of the landscape, forests, and vegetation within human settlements. The results indicate a 4.4 to $14 \%$ decline in forest cover and a 35 to $40 \%$ increase in developed land between 2005 and 2050 (Reinmann et al 2016 and Yang et al 2017). In addition, Song et al suggested that the changes in land use and land cover considerably damage the Earth's energy balance and biogeochemical cycles. The damage contributes to climate change and in turn affects land surface properties and the provision of ecosystem services (Song et al 2016; Payn et al 2015 and Mahmood \& Mayo, 2016). More collectively, scholars suggest that land cover, aquifer recharge, and impervious area effects urban flood considerably (Nachshon et al 2016 and Nath et al 2020). Shaw is right when she recommended a higher elevation in the urban constructions (Shaw, 2005). In urban development, hydrological knowledge is required in two phases. The first is the planning stage to consider a higher elevation for the buildings. The second step of the hydrological involvement occurs at the detailing stage, the designing of the drainage channels and pipes to carry the surface water into the rivers. The design of the drainage system is dependent on a careful assessment of the flood size and return period of the flood. When cities are becoming increasingly vulnerable to flooding, the design of the drainage channels is vital.

Until now, we analyzed dialectically urban expansion effects on urban hydrology and floods multidimensional. We recognized that urban development has multifaceted effects on the floods. The studies illustrated that urban development is influential on the aquifers, the drainage systems, the climate characteristics, and the area of the forests.

Theoretical studies guide us that essential projects in the urban development process are needed to manage the floods optimally. We concluded that planners, designers, entrepreneurs, and urban management must take certain actions to make optimal use of the rains and floods. Their ultimate goal is to protect the cities against highly destructive floods. The required projects are determined through workshop experiences and exploration of the ideas of the relevant scholars and practicing. Please see Table 1 for a list of required projects to manage and control the floods optimally. At the same time, we use the situation of the projects as indicators to assess the degree of success in flood management. 
Table 1. A list of projects shall be performed to control urban floods

\begin{tabular}{|l|l|c|}
\hline Line & \multicolumn{1}{|c|}{ Name of projects/Indicators } & $\begin{array}{l}\text { Abbreviatio } \\
\mathrm{n}\end{array}$ \\
\hline 1 & Demographic development, including population and family planning & PF \\
\hline 2 & Building and managing flood control hydraulic structures & FD \\
\hline 3 & $\begin{array}{l}\text { Planning and performance of preventive projects. Implementation of } \\
\text { the aquifer and watersheds plans sufficient to control the flood in the } \\
\text { primary areas }\end{array}$ & DP \\
\hline 4 & $\begin{array}{l}\text { Protecting of riversides and depth of rivers and drainages. Also, } \\
\text { peeling channels and drain valves of dams }\end{array}$ & MF \\
\hline 5 & $\begin{array}{l}\text { Maintaining forests and meadows and avoid changing land use in } \\
\text { villages }\end{array}$ & TL \\
\hline 6 & $\begin{array}{l}\text { Determine the correct topographic location for construction. Avoid } \\
\text { developing cities in places lower than the seawater level }\end{array}$ & BR \\
\hline 7 & $\begin{array}{l}\text { Build cities resilient and respect the indices and standards of resilient } \\
\text { cities to control floods. }\end{array}$ & \\
\hline
\end{tabular}

\section{Methodology and case studies}

\subsection{Methodology}

The theoretical studies of this research provided a framework to guide field studies in the form of a case study strategy. The field studies are knowledge-based as earlier has been presented by Shahraki for the sake of regional/urban sustainable development (Shahraki, 2019). This research supposes that when the flood management model is knowledge-based and optimal, it will not be hazardous. On the contrary, the flood will be beneficial in sustainable urban development. Thus, the main method of this research is to suggest an optimal natural-based flood management model. This research examines the current flood management procedures as one alternative model to introduce its failures and weaknesses. Procedures to manage floods optimally include projects that have been listed in Table 1 . Theoretical studies on seven indicators had both generic and local features. The indicators are suitable for the characteristics of the case study areas. A benchmarking technique has been used to compare the current flood management model to the optimal natural-based 
model. Shahraki applied the technique in a work titled "Analyzing economic policies related to effects of immigrant labor" (Shahraki, 2017). In this case study, the indicators have been evaluated and scored for the two alternatives with the help of structured interviews and regional cognition. The indicators are investigated in nine cities located in the nine regions of Iran. The cities are Ardabil located in the northwest, Rasht in the north, Aggala in the northeast, Mamoulan in the west, Golshahr in the central, Hirmand in the east, Shiraz in the southwest, Abarkooh in the south, and Fanouj in the southeast parts of the country. The case studies analyze, evaluate, and compare the situation of flood management in the nine regions of Iran to what the scholars and scientists recommend as an optimal alternative model. To foster the comparisons between the situations of flood managing in Iran and the optimal alternative writing polls and questionnaires about the seven indicators have been used. We gathered the ideas of responders on (PF), (FD), (PP), (DP), (MF), (TL), and (BR). Our statistical population consisted of 600 flood-affected people living in the mentioned nine cities in Iran. The questionnaires were filled in through the structured interviews. The situations of the indicators have been assessed with the help of the ideas of the flooded people, field observations, and experiences. The questionnaires recorded the opinions of flood-affected people and flood control experts concerning the seven indicators. Afterward, the data were categorized and results are extracted. It has been determined that to what degree every indicator has been respected in Iran. To provide the assessments, the questionnaire had five options to write down the responses. Those five options were; Very bad, bad, no idea, good, and very good equal to $-10,-5,0,+5$, and +10 respectively. Then, the benchmarking technique as a comparative tool has been used. The benchmarking technique has also been used to analyze all suggested and recommended projects in the two flood control alternative models. Finally, some projects under the umbrella of natural-based optimal flood control and management model have been suggested to meet the goal.

\subsection{Case studies}

The case studies are concerning two subjects. First, to see how much climate change influences the floods. Second, to see to what degree the seven indicators have been respected in urban flood management.

\section{Climate change in Iran}

Iran's environment has become critical due to the increased population and urbanization. Droughts, water scarcity, deforestation, eradication of pastures, sewage flows in the streets and passageways, air pollution, and the reduction of the number of fauna and flora from the 
marine ecosystems in Iran are some marks of the degradation of the environmental components. Iranian scientists believe that the environmental components are being degraded by the lack of funds and knowledge-based management as well. They believe that the wornout automobiles and none standard petrol and gasoline degrade the environment as well. On the other side, there is still no theory about considerable climate change in Iran. As some sample indicators, an increase in the average temperature, an increase in the surface water level of the seas and the arrival of water to ports has not been yet reported in Iran. Soltani and colleagues made a study in Iran related to climate modification during 1975-2010. They divided the country into nine parts and surveyed the trends of climate indices. The result of their observations related to the changes in temperatures states that the highest temperature rise was +0.067 degrees. Other scholars made a comparison between the past and future climatic trends of Iran. They suggested that temperature would increase and precipitation decrease under the effect of greenhouse gas emissions caused by urbanization (Zohrabi et al 2014). On the other hand, the number of severe and destructive floods in Iran has increased significantly in recent years (Hosseini et al 2020 and Samimi et al 2020). These facts in Iran suggest that the cause of both slight climatic changes and recent destructive floods might be in human behavior with nature.

\section{$i \quad$ Analysis of the seven indicators}

The population of Iran has increased steadily. The increased demands for the required urban places degrade the rivers, drainages, and forests. Table 2 shows the responses of the questioned people about the success of the demographic development programs in Iran.

Table 2. Ideas of the flooded people about PF (per percent)

\begin{tabular}{|c|l|l|l|l|l|}
\hline Evaluation of the Responses & $\begin{array}{l}\text { Very } \\
\text { bad, } \\
-10\end{array}$ & $\begin{array}{l}\text { Bad, } \\
-5\end{array}$ & $\begin{array}{l}\text { No } \\
\text { idea, } \\
0\end{array}$ & $\begin{array}{l}\text { Good, } \\
+5\end{array}$ & $\begin{array}{l}\text { Very } \\
\text { good, } \\
+10\end{array}$ \\
\hline Percent of the responders & 81 & 5 & 2 & 8 & 2 \\
\hline
\end{tabular}

According to the studies majority of people, $86 \%$, believe that policies related to the demographic development have, PF, failed and the situation of flood control gets worse considering this indicator.

There are some hydraulic structures such as 588 dams, some tidal barrage diversion canals, and coastal defenses in Iran, but they have major shortages. Some lack is short feasibility 
studies, structural corruption, inefficiency, and none environmental standards. Regarding this index, the responders evaluated it as Figure 3 illustrates.

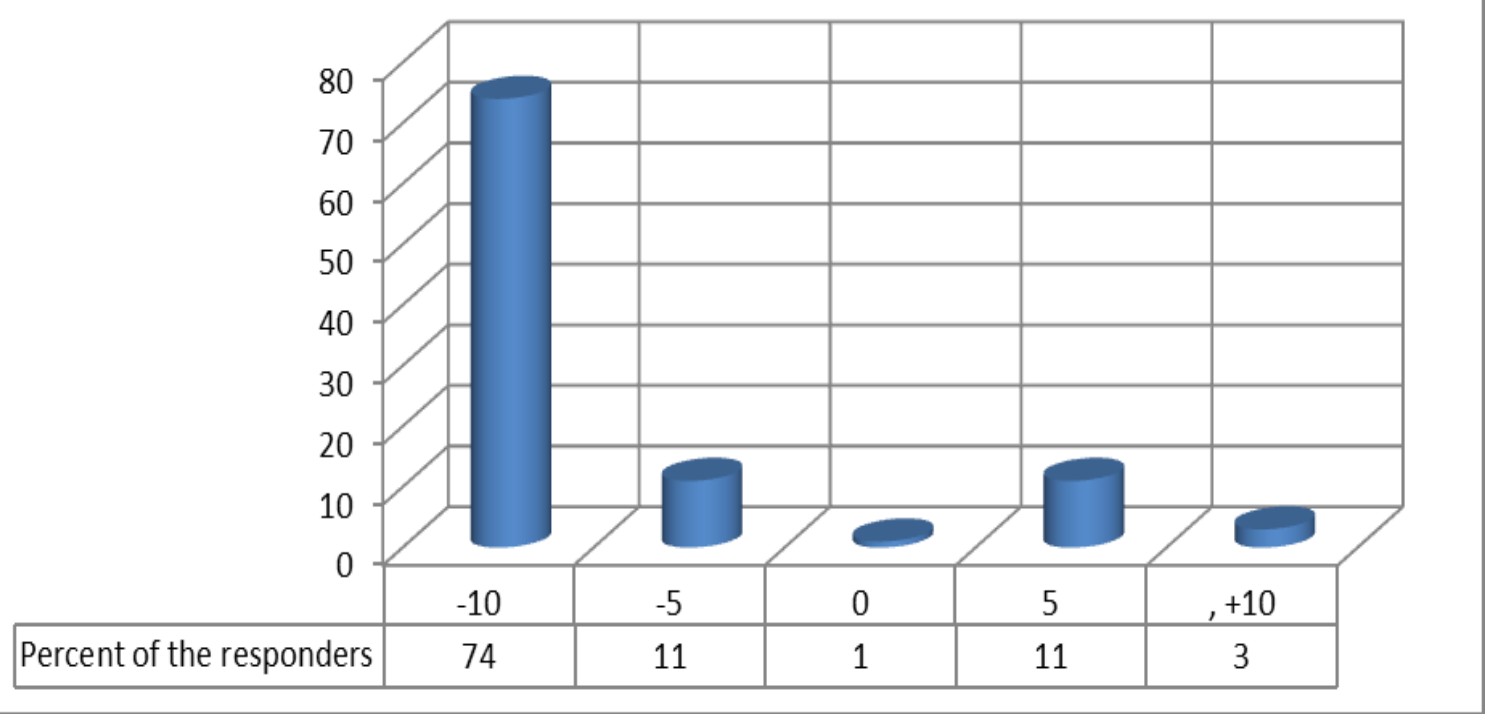

Figure 3. Ideas of flooded people about the FD (per percent)

Figure 3 shows a high percentage of the flooded people, $85 \%$, believe that the FD index is weak and not in a situation to control the floods optimally.

Our observation and experiences reveal that the quantity and quality of preventive projects in terms of the aquifers and watersheds to control the floods in the primary areas are very low. The authorities did neglect the importance of watershed management over the past decades. The reductions of water resources, conflict of interests, and neglect of local communities have caused floods and major losses. The responders evaluated the indicator as Figure 4 illustrates.

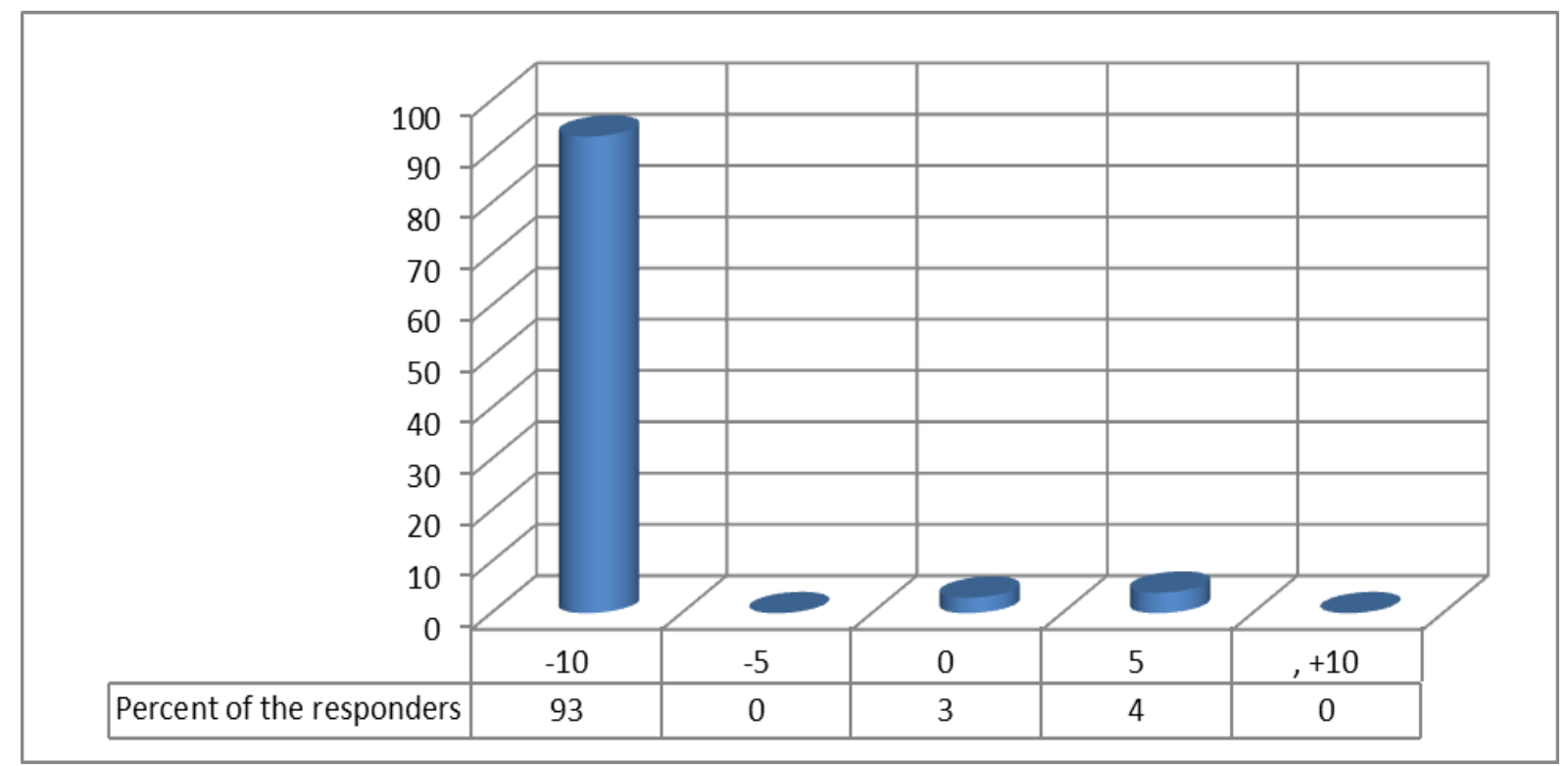

Figure 4. Ideas of the flooded people about the PP 
The above table states a high degree, 93\%, of dissatisfaction among the flooded people about the PP index. Before the flood, rivers, water channels, and valley floods were full of mud and sediments like cities of Aghala and Gomishan in the northern strip of the country. In the southeastern part of Iran like the city of Shiraz, the flood revealed that the corrupted municipality had constructed in the riverbed. About this index (DP), the responders evaluated as Figure 5 shows.

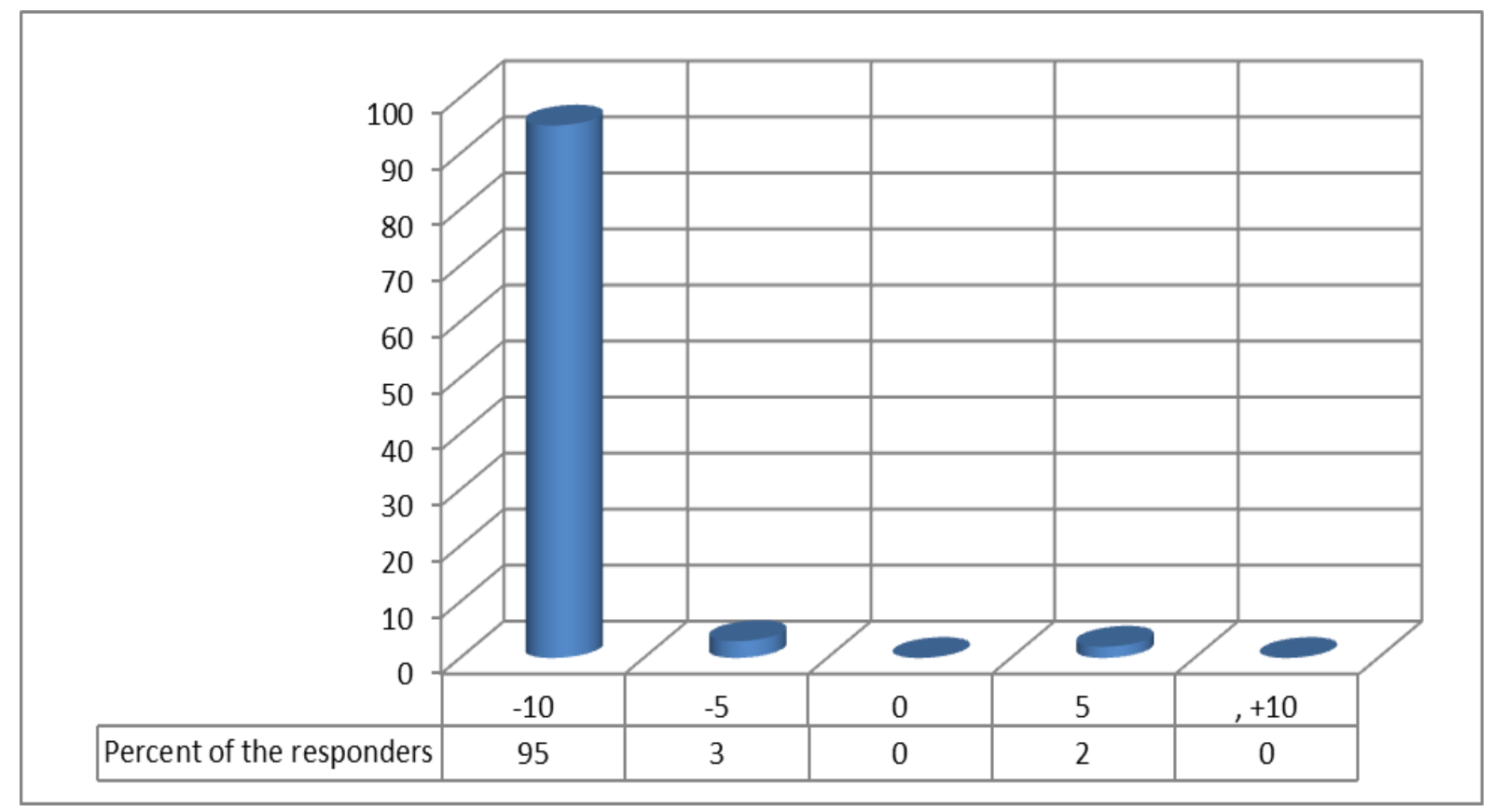

Figure 5. Ideas of the flooded people about the DP (per percent)

Figure 5 shows that almost $98 \%$ of the flooded people believe that the DP index has a catastrophic situation. Rangelands of Iran have been under erosion for various reasons, including excessive use of groundwater resources through traditional agriculture .This has severely increased the vulnerability of the lands to floods. Meanwhile, incorrect use of forest trees in northern regions such as Gilan, Mazandaran, and Golestan provinces has reduced the forest area. In addition, the forests of the Zagros Mountain Range were also greatly reduced by the corrupt and thieves' gangs to export timbers. Another phenomenon in recent decades has been the new rich bureaucrat cast, who invaded the northern forests of Iran to build recreational villas and facilities. The destruction of forests and vegetation on the slopes of the mountains has greatly reduced the durability time of rains on the surface of the earth. That is why the floods quickly enter the cities (Tehran times, 2019). Regarding this index, the responders assessed it as Figure 6 illustrates. 


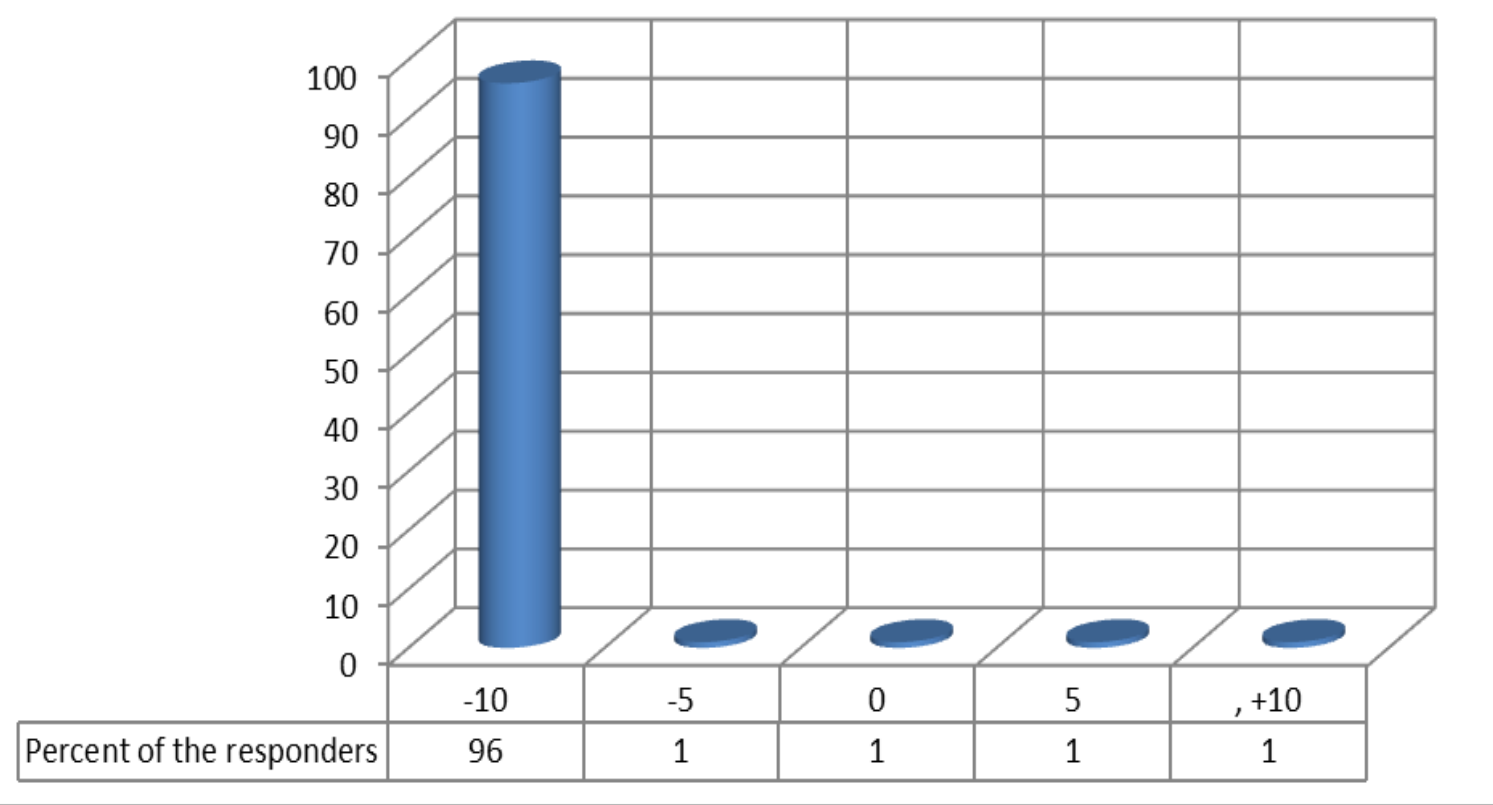

Figure 6. Ideas of the flooded people about the MF (per percent)

Some $97 \%$ of the flooded people expressed their insufficient opinions. Therefore, the MF index has likewise a catastrophic situation.

Originally, most of Iran's cities are ancient villages created for a small population. With the population increasing, people rushed to sloping fields, dead bed lands, and sloping slopes of the hills to build shelters. Although Iran has a set of national construction laws, codes, standards, and regulations, the existing organized corruption in municipalities and urban authorities has led to chaos and unsustainable urban development. Government departments do not recognize the importance of research and development, R\&D either. The feasibility and effects of projects on the environmental components are not studied. The newly built environments might be built on the bed of watercourses and rivers, as well as on sloping lands and mountain slopes. Such actions increased the flood's causalities. Concerning this index, the responders evaluated it as Figure 7 illustrates. 


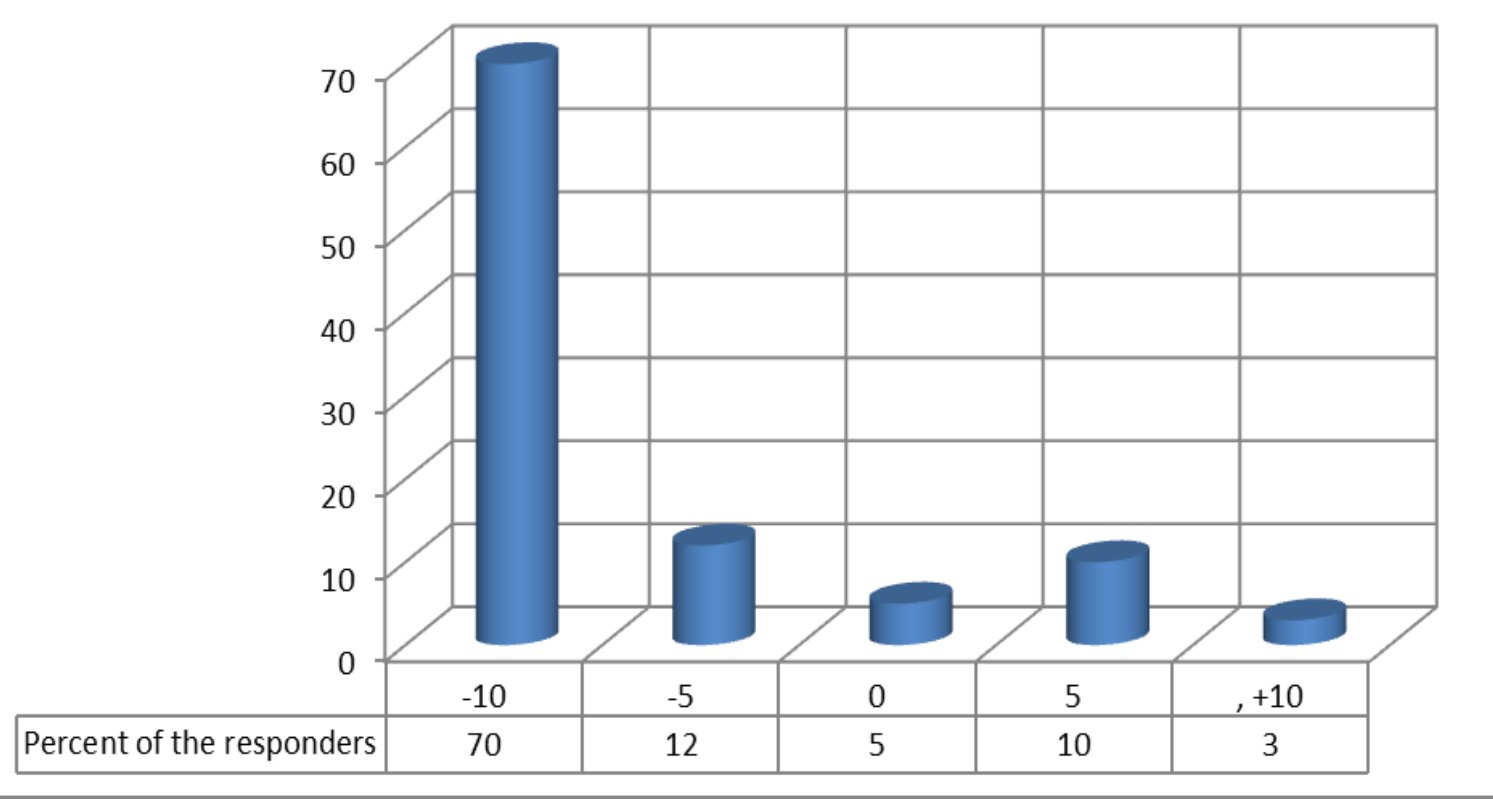

Figure 7. Ideas of the flooded people about the TL (per percent)

Figure 7 states a high degree, almost $82 \%$, of discontent among the flooded people about the TL index.

In recent decades, there has been no investment in urban knowledge-based projects.

Generally, the population of Iran has suffered greatly from a lack of proper regional/urban planning. The increased density puts pressure on the built environments in coastal lowlands, along with unstable slopes, and in hazard-prone areas are some of the risks. Another significant risk driver in Iran is the corrupted and weak local governance and insufficient public participation. Inadequate and incompetent water resources management is one more important risk driver. The short drainage and waste management cause floods and landslides too. The decaying infrastructure and unsafe building stocks that lead to collapsed structures in flooding times are also risk drivers in Iranian urban areas. During the last floods in Iran, uncoordinated emergency services that decreased the capacity for swift response and preparedness has been revealed as well. Worse, urban management in Iran has no plans to create resilient cities! The responders assessed this indicator as Figure 8 illustrates. 


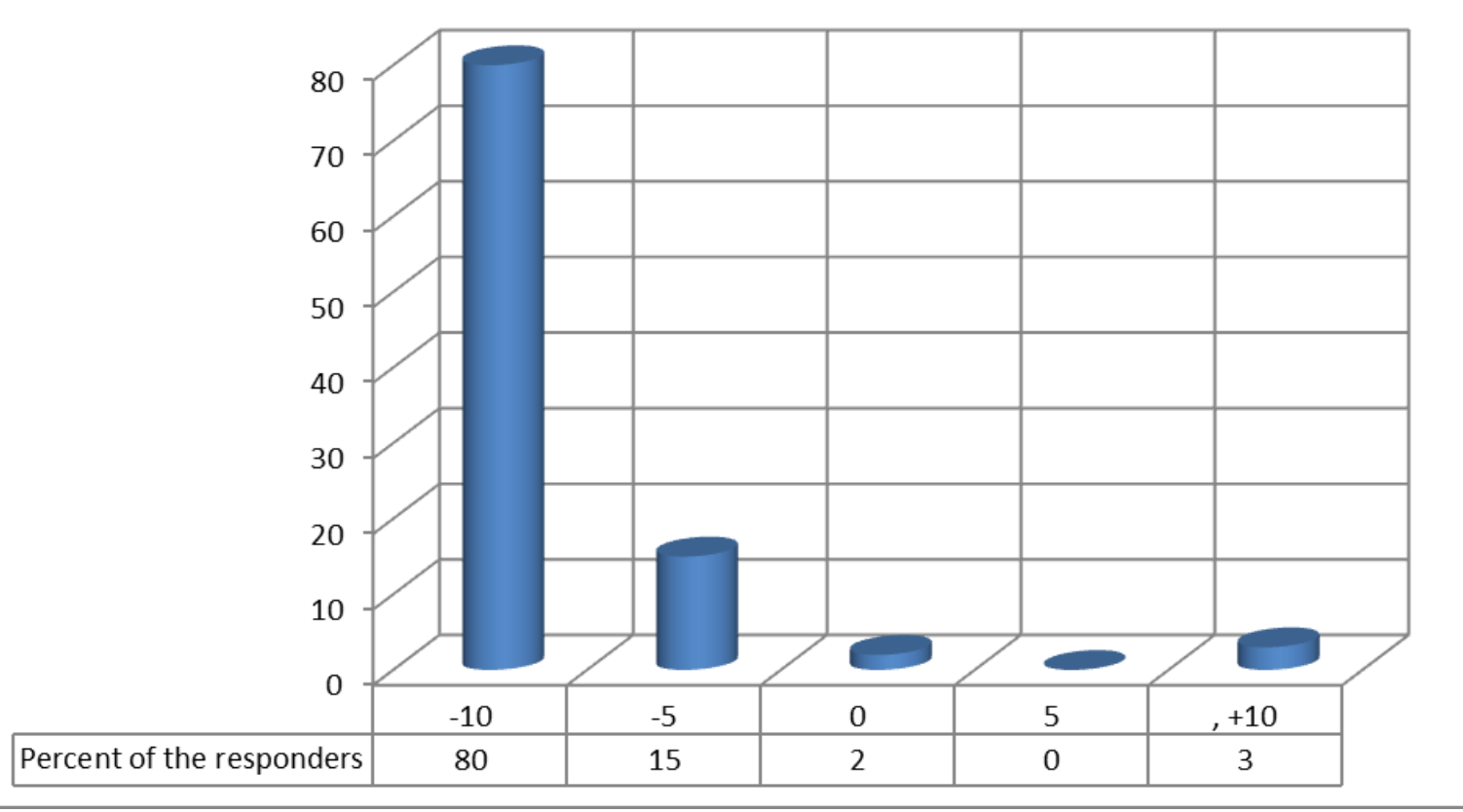

Figure 8. Ideas of the flooded people about the BR (per percent)

As Figure 8 exhibits, the BR indicator is very weak. The majority of people, $95 \%$ are annoyed. Almost $80 \%$ of the people gave the score of- 10 .

\section{Discussions and comparisons}

The observations and field studies concerning the seven indicators proved that urban flood management in Iran has been unsuccessful. Although Iran has always faced destructive floods, the authorities have not come up with any proper remedial plan for this problem. Experiences and observations show that flood control and management have not been institutionalized as a problem in the minds of the authorities. In addition, improvement of the quality of urban life is not the priority of the municipal budgets. Our field studies show that flood management is not a priority on the government's agenda. For this reason, 85 to 98 percent of the flooded people evaluated the flood management very bad and weak, -10 . To understand precisely the situation of flood management in Iran, two following alternative models have been compared:

1- The existing situation of flood management in Iran

2- Optimal natural-based flood management

The two alternatives are for comparison between what the flood control situation is and what should be. In the first alternative, we consider the percentage of the flooded people, who have expressed their disappointment over the management of the flood by assigning a very 
bad score, -10. The second alternative is a natural-based procedure. We established this alternative based on the advice of scholars in the theoretical guide and assume that optimal flood management has got scores of 100 in all indicators. Here, we compare the two flood management alternatives. The following figure exhibits the result.

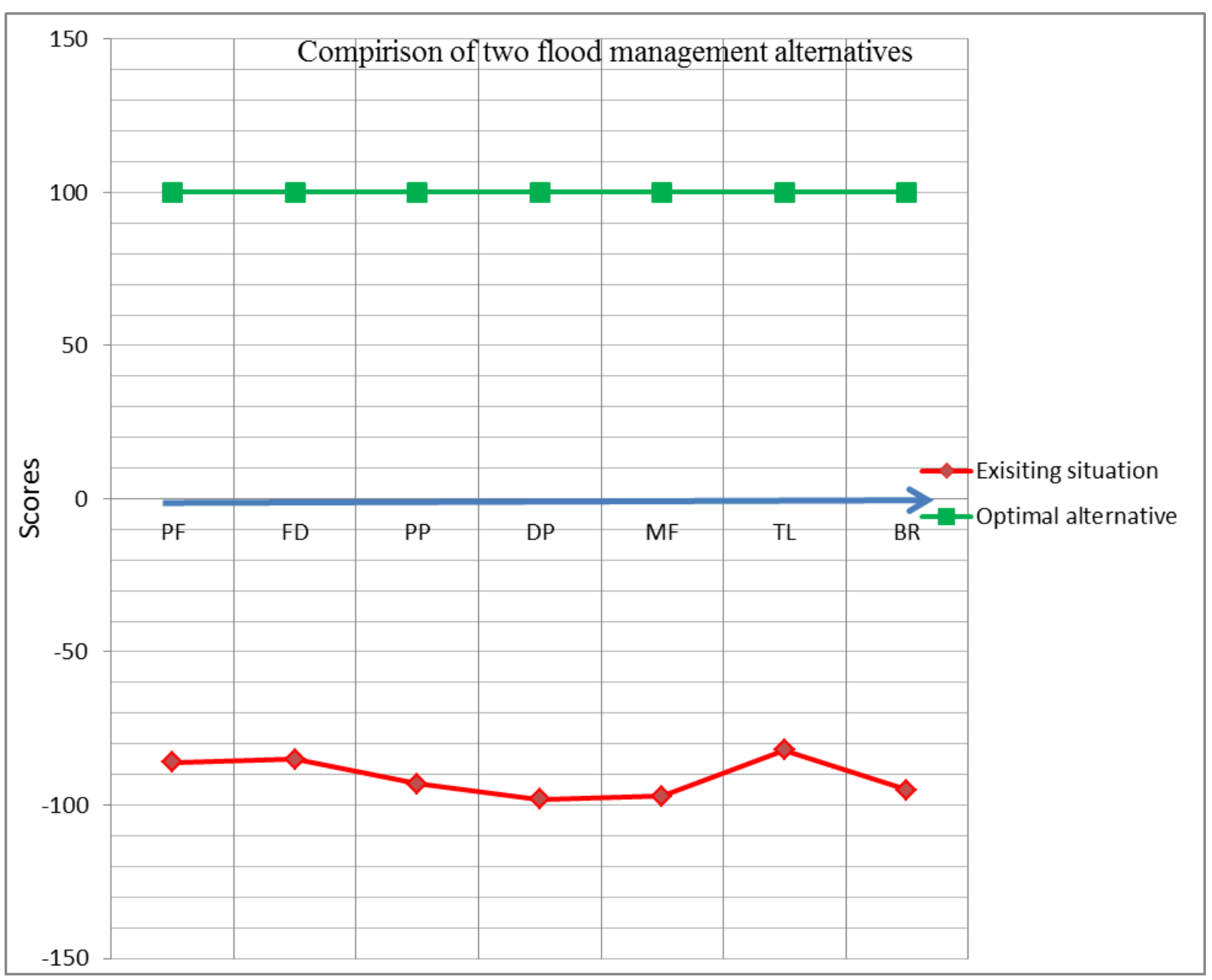

Figure 9. Comparison of seven indicators in two flood control alternatives

In Figure 9, the red curve represents the percentage of the responders, who are annoyed with the situation of the existing flood management in Iran. The percentages are shown above the red curve for every indicator with a negative sign. The scores attributed to the indicators are $86,-85,-93,-98,-97,-82$ and -95 respectively. The blue line with zero scores for all indicators shows a situation without any action. From the geometric point of view, the boundary between the red curve and the blue line is the area that we call it the destructive and deadly flood risk areas.

The green line, in the same way, represents the PF, FD, PP, DP, MF, TL, and BR indicators related to the natural-based optimal flood management alternative. From the geometric point of view, the boundary between the red curve and the green line is the area that we call it the distance area between what is and what shall be the situation of flood management. 
The boundary covers -98 to +100 and shows the necessity to progress the situation of the existing flood management in Iran up to the natural-based optimal situation without any risk. The progress shall be in all the seven mentioned indicators. The comparison of the two flood management alternatives exhibited that the increased populations, the expansion of urban areas, and human behaviors against the ecosystems and natural resources caused the destructive and deadly floods. This finding proves the validity of the hypothesis of this research that poor flood management led to the deadly, devastated, and hazardous floods. The case studies have also shown us that the slight climate change caused by environmental degradation has also been the result of inefficient management.

\section{Conclusions}

The deadly and destructive floods in the Middle East, including Iran in late March and April 2019 , have raised many debates to identify the causes of the floods in the cities. We theorized that poor official flood management was the major reason. This study aimed to prove the hypothesis. This research applied the theoretical studies to provide a guideline for the sake of the case studies in Iran and to present an optimal and nature-based flood management model. We examined seven indicators in the flooded areas. The guideline was supported by theories of the relevant scholars and global successful experiences. This study noticed that the natural environmental components of Iran have been destroyed continuously. With the introduction of the two flood management alternative models and the use of a benchmarking technique, we found that the existing flood management in Iran is very weak. This fact was revealed by referring to the ideas of the flooded people. We found that the major responsible factor for the floods was the official authorities. This paper suggested a knowledge-based, wellfounded, and successful flood management model with the help of certain indicators. Since the indicators have general features, the model is applicable to flood control and management everywhere in the world. 


\section{References:}

Chan, F. K. S., Chuah, C. J., Ziegler, A. D., Dąbrowski, M., \& Varis, O. (2018). Towards resilient flood risk management for Asian coastal cities: Lessons learned from Hong Kong and Singapore. Journal of Cleaner Production, 187, 576-589.

Corbau, C., Zambello, E., Rodella, I., Utizi, K., Nardin, W., \& Simeoni, U. (2019). Quantifying the impacts of the human activities on the evolution of Po delta territory during the last 120 years. Journal of environmental management, 232, 702-712.

Fekete, B. M., \& Bogárdi, J. J. (2015). Role of engineering in sustainable water management. Earth Perspectives, 2(1), 2

Fetter, C. W. (2018). Applied hydrogeology. Waveland Press.

Ghobadi, M., \& Kaboli, H. S. (2020). Developing a Web-based decision support system for reservoir flood management. Journal of Hydroinformatics, 22(3), 641-662.

Han, L., Xu, Y., Lei, C., Yang, L., Deng, X., Hu, C., \& Xu, G. (2016). Degrading river network due to urbanization in Yangtze River Delta. Journal of Geographical Sciences, 26(6), 694-706.

Hong, H., Panahi, M., Shirzadi, A., Ma, T., Liu, J., Zhu, A. X., ... \& Kazakis, N. (2018). Flood susceptibility assessment in Hengfeng area coupling adaptive neuro-fuzzy inference system with genetic algorithm and differential evolution. Science of The Total Environment, 621, 1124-1141.

Hosseini, F. S., Choubin, B., Mosavi, A., Nabipour, N., Shamshirband, S., Darabi, H., \& Haghighi, A. T. (2020). Flash-flood hazard assessment using ensembles and Bayesian-based machine learning models: application of the simulated annealing feature selection method. Science of the total environment, 711, 135161.

Iran Water Resources Management Co. 2019. Accessible online at: http://dams.wrm.ir/

Mahmood, S., \& Mayo, S. M. (2016). Exploring underlying causes and assessing damages of 2010 flash flood in the upper zone of Panjkora River. Natural Hazards, 83(2), 1213-1227،

Metal, M. (2017). Tailoring Green Storm water Infrastructure to Hawiian Landscapes. Pp 11.

Miller, J. D., \& Hutchins, M. (2017). The impacts of urbanisation and climate change on urban flooding and urban water quality: A review of the evidence concerning the United Kingdom. Journal of Hydrology: Regional Studies, 12, 345-362.

Müller-Navarra, K., Milker, Y., Bunzel, D., Lindhorst, S., Friedrich, J., Arz, H., \& Schmiedl, G. (2019). Evolution of a salt marsh in the southeastern North Sea region-Anthropogenic and natural forcing. Estuarine, Coastal and Shelf Science, 218, 268-277.

Nachshon, U., Netzer, L., \& Livshitz, Y. (2016). Land cover properties and rain water harvesting in urban environments. Sustainable cities and society, 27, 398-406. 
NASA Earth Observatory images by Lauren Dauphin, using MODIS data from NASA EOSDIS/LANCE and GIBS/Worldview. accessible online at https://earthobservatory.nasa.gov/images/144785/floods-ravage-iran-and-iraq

Nath, B., Ni-Meister, W., \& Choudhury, R. (2020). Impact of urbanization on land use and land cover change in Guwahati city, India and its implication on declining groundwater level. Groundwater for Sustainable Development, 100500.

Pakmehr, S., Yazdanpanah, M., \& Baradaran, M. (2020). How collective efficacy makes a difference in responses to water shortage due to climate change in southwest Iran. Land Use Policy, 99, 104798.

Payn, T., Carnus, J. M., Freer-Smith, P., Kimberley, M., Kollert, W., Liu, S., ... \& Wingfield, M. J. (2015). Changes in planted forests and future global implications. Forest Ecology and Management, 352, 57-67.

Peng, J., Tian, L., Liu, Y., Zhao, M., \& Wu, J. (2017). Ecosystem services response to urbanization in metropolitan areas: Thresholds identification. Science of the Total Environment, 607, 706-714.

Pourghasemi, H. R., Gayen, A., Edalat, M., Zarafshar, M., \& Tiefenbacher, J. P. (2020). Is multi-hazard mapping effective in assessing natural hazards and integrated watershed management?. Geoscience Frontiers, 11(4), 1203-1217.

Raso, L., Chiavico, M., \& Dorchies, D. (2019). Optimal and centralized reservoir management for drought and flood protection on the Upper Seine-Aube river system using stochastic dual dynamic programming. Journal of Water Resources Planning and Management, 145(3), 05019002.

Reinmann, A. B., Hutyra, L. R., Trlica, A., \& Olofsson, P. (2016). Assessing the global warming potential of human settlement expansion in a mesic temperate landscape from 2005 to 2050. Science of the Total Environment, 545, 512-524.

Rogger, M., Agnoletti, M., Alaoui, A., Bathurst, J. C., Bodner, G., Borga, M., ... \& Holden, J. (2017). Land use change impacts on floods at the catchment scale: Challenges and opportunities for future research. Water resources research, 53(7), 5209-5219.

Salimi, M., \& Al-Ghamdi, S. G. (2020). Climate change impacts on critical urban infrastructure and urban resiliency strategies for the Middle East. Sustainable Cities and Society, 54, 101948.

Samimi, S., Ebrahimnejad, S., \& Mojtahedi, M. (2020). Analysis of the susceptibility of interdependent infrastructures using fuzzy input-output inoperability model: the case of flood hazards in Tehran. Natural Hazards, 100(1), 69-88.

Shahraki, A. A. (2015). Water planning and management in sustainable new town building, the case of Ramshar. International Journal of Water Resources and Environmental Engineering, 7(9), 115-122. 
Shahraki, A. A. (2017). Analysing Economic Policies Related to Effects of Immigrant Labour with Case Studies. International Journal of Research in Sociology and Anthropology (IJRSA) Volume 3, Issue 4, 2017, PP 1-11

Shahraki. A. A. (2019). Sustainable regional development through knowledge networks; Reflection of case studies International Journal of Frontiers of Architectural Research. FOAR-D-19-00051

Shaw, E. (2005). Hydrology in practice. CRC Press.

Singh, A. (2019). Poor-drainage-induced salinization of agricultural lands: Management through structural measures. Land Use Policy, 82, 457-463.

Soltani, M., Laux, P., Kunstmann, H., Stan, K., Sohrabi, M. M., Molanejad, M., ... \& ZawarReza, P. (2016). Assessment of climate variations in temperature and precipitation extreme events over Iran. Theoretical and Applied Climatology, 126(3-4), 775-795.

Song, X. P., Hansen, M. C., Stehman, S. V., Potapov, P. V., Tyukavina, A., Vermote, E. F., \& Townshend, J. R. (2018). Global land change from 1982 to 2016. Nature, 560(7720), 639.

Spaans, M., \& Waterhout, B. (2017). Building up resilience in cities worldwide-Rotterdam as participant in the 100 Resilient Cities Programme. Cities, 61, 109-116.

Tehran times (2019). Silent death: Zagros Mountains forest plagued by deforestation, degradation. Published by Tehran times leading international newspaper. January 26, 2019.

The World Bank 2017. Urban population.

Tockner, K., \& Stanford, J. A. (2002). Riverine flood plains: present state and future trends. Environmental conservation, 308-330.

Walsh, C. J., Booth, D. B., Burns, M. J., Fletcher, T. D., Hale, R. L., Hoang, L. N., \& Wallace, A. (2016). Principles for urban stormwater management to protect stream ecosystems. Freshwater Science, 35(1), 398-411.

Wang, Y., Ji, W., Yu, X., Xu, X., Jiang, D., Wang, Z., \& Zhuang, D. (2014). The impact of urbanization on the annual average temperature of the past 60 years in Beijing. Advances in Meteorology, 2014

Yadollahie, M. (2019). The flood in Iran: a consequence of the global warming?. The international journal of occupational and environmental medicine, 10(2), 54.

Yang, J., Sun, J., Ge, Q., \& Li, X. (2017). Assessing the impacts of urbanization-associated green space on urban land surface temperature: A case study of Dalian, China. Urban Forestry \& Urban Greening, 22, 1-10.

Zhang, X. Q. (2016). The trends, promises and challenges of urbanization in the world. Habitat International, 54, 241-252. 
Zohrabi N, Bavani AM, Goodarzi E, Eslamian S (2014) Attribution of temperature and precipitation changes to greenhouse gases in northwest Iran. Quatern Int 345:130-137. https://doi.org/10.1016/j.quaint.2014.01.026 